\title{
Correction to: Glycerol metabolism and its regulation in lactic acid bacteria
}

\section{Yuki Doi ${ }^{1}$}

Published online: 31 May 2019

(C) Springer-Verlag GmbH Germany, part of Springer Nature 2019

\section{Correction to: Applied Microbiology and Biotechnology https://doi.org/10.1007/s00253-019-09830-y}

The original publication of this paper contains some errors.

1) The bacterial name "Lactococcus alimentarius" in Fig. 2 is incorrectly presented. The correct name is "Lactobacillus alimentarius."

2) In the paragraph on "Genetic organization and regulation of glycerol metabolism genes in lactic acid bacteria," the G3P-oxidizing enzyme and its corresponding gene in Lactococcus lactis subsp. cremoris and Lactobacillus alimentarius are incorrectly substituted. The corrected sentences are as follows:

However, the phylogenetic tree analysis of the LAB listed in Table 1 indicated that Lactococcus lactis subsp. cremoris and Lactobacillus alimentarius contain GlpA and GlpD, respectively (Fig. 2). LAB's glpO or L. lactis subsp. cremoris's $g l p A$ constitute operons along with the $g l p K$ and $g l p F$ (encoding glycerol facilitator protein GlpF), except for $L$. alimentarius's $g l p D$ (Fig. 3).
3) In Table 1, "glpD” of Lactococcus lactis subsp. cremoris in the G3P oxidation column is incorrect; the correct term is " $g l p A$." The $g l p A$ encodes anaerobic G3P dehydrogenase subunit A.

4) In Fig. 3a, the " $g l p K D F$ operon" is incorrect; the correct term is " $g l p K A F$ operon."

5) In Table 2, "glpKDF" of Lactococcus lactis subsp. cremoris in the operon column is incorrect; the correct term is " $g l p K A F . "$

6) In Table 2, the strain name "SF11" of Lactococcus lactis subsp. cremoris is incorrectly presented. The correct strain name is "SK11."

Publisher's note Springer Nature remains neutral with regard to jurisdictional claims in published maps and institutional affiliations.

The online version of the original article can be found at https://doi.org/ 10.1007/s00253-019-09830-y

Yuki Doi

yuki.doi.doct@gmail.com

1 Department of Applied Chemistry and Biotechnology, Faculty of Engineering, Okayama University of Science, Okayama 700-0005, Japan 